\title{
Whole-body resting and exercise-induced lipolysis in sarcopaenic patients with COPD
}

\author{
F.M.E. Franssen*, H.P. Sauerwein\#, E.P.A. Rutten*, \\ E.F.M. Wouters* and A.M.W.J. Schols*
}

ABSTRACT: Impaired $\beta$-adrenoceptor-mediated lipolysis has been reported in sarcopaenic chronic obstructive pulmonary disease (COPD) patients. This could play a role in the shift in body composition towards decreased fat-free mass (FFM) and relative maintenance of fat mass (FM). Lipolysis could be affected by chronic treatment with $\beta_{2}$-agonists or disease-related factors. Therefore, whole-body resting and exercise-induced lipolysis were investigated in sarcopaenic COPD patients with moderate disease severity.

Seven sarcopaenic COPD patients (mean \pm SEM forced expiratory volume in one second (FEV 1 ) $53 \pm 5 \%$ of the predicted value; body mass index (BMI) $27.5 \pm 0.9 \mathrm{~kg} \cdot \mathrm{m}^{-2}$ ) and seven controls matched for age, sex and BMI were studied. In addition, six underweight COPD patients (FEV 1 $51 \pm 5 \%$ pred; BMI $20.6 \pm 0.7 \mathrm{~kg} \cdot \mathrm{m}^{-2}$ ) matched for disease severity were recruited. Lipolysis and plasma levels of catecholamines were assessed during infusion of $\left[{ }^{2} \mathrm{H}_{5}\right]$ glycerol at rest and during submaximal cycling exercise.

The proportional FM was comparable between sarcopaenic patients and controls, whereas the FFM index was significantly reduced in patients. At rest, the rate of appearance $(R a)$ of glycerol (4.1 \pm 0.6 and $3.3 \pm 0.2 \mu \mathrm{mol} \cdot \mathrm{kg} \mathrm{FFM}^{-1} \cdot \mathrm{min}^{-1}$, respectively) did not differ significantly. In underweight patients, glycerol $R a\left(4.3 \pm 0.5 \mu \mathrm{mol} \cdot \mathrm{kg} \mathrm{FFM}^{-1} \cdot \mathrm{min}^{-1}\right)$ was also comparable. End-of-exercise lipolytic rates did not differ significantly between groups. Glycerol Ra was not related to FM. Resting adrenalin levels were significantly increased in underweight COPD patients and were related to resting lipolysis.

Sarcopaenia in chronic obstructive pulmonary disease patients with moderate disease severity is not characterised by an abnormal lipolytic rate. Altered regulation of muscle protein turnover seems to be the trigger in the body compositional shift observed in these patients.

KEYWORDS: Body composition, chronic obstructive pulmonary disease, exercise, fat mass, intermediary metabolism, lipolysis

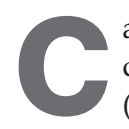
achexia, defined as weight loss with a disproportional loss of fat-free mass (FFM), occurs in a substantial number of patients with chronic obstructive pulmonary disease (COPD) and is an independent predictor of mortality [1]. Its prevalence depends upon the population analysed, and ranges from $11 \%$ in moderate-to-severe COPD outpatients [2] to $26 \%$ in severe patients eligible for pulmonary rehabilitation [3]. Furthermore, in a substantial proportion $(10-15 \%)$ of normal-weight COPD patients, hidden depletion of FFM occurs [3, 4], also referred to as sarcopaenia. The clinical implications of this body compositional shift towards decreased FFM and relative or even absolute abundance of fat mass (FM) were illustrated in a study showing a greater degree of physical impairment in normal-weight COPD patients with low FFM compared to underweight patients with preserved FFM [3]. It was hypothesised that sarcopaenia in COPD is associated with alterations in intermediary metabolism, towards accelerated net muscle protein breakdown and impaired fat oxidation or decreased lipolysis. There are some indications that depletion of FFM is indeed associated with altered regulation of protein turnover towards increased protein breakdown [5-7]. In addition, reduced skeletal muscle activity of 3-hydroxyacyl CoA dehydrogenase, which regulates the $\beta$-oxidation of fatty acids, has consistently been shown in normalweight COPD patients [8]. Finally, an impaired $\beta$ adrenoceptor-mediated increase in plasma levels of nonesterified fatty acids was reported in sarcopaenic COPD patients [9], which is suggestive of reduced lipolysis. However, whole-body
AFFILIATIONS

*Dept of Respiratory Medicine, NUTRIM School for Nutrition, Toxicology and Metabolism, Maastricht University Hospital, Maastricht, and

\#Dept of Endocrinology and Metabolism, Academic Medical Center, Amsterdam, the Netherlands.

CORRESPONDENCE

F.M.E. Franssen

Dept of Respiratory Medicine University Hospital Maastricht P.0. Box 5800

6202 AZ Maastricht

The Netherlands

Fax: 31433875051

E-mail: f.franssen@pul.unimaas.nl

Received:

January 292008

Accepted after revision:

June 122008

STATEMENT OF INTEREST

Statements of interest for H.P. Sauerwein, E.F.M. Wouters and A.M.W.J. Schols and the study itself can be found at

www.erj.ersjournals.com/misc/ statements.shtml

European Respiratory Journal Print ISSN 0903-1936 Online ISSN 1399-3003 
lipolytic rate and differences in lipid kinetics between sarcopaenic and underweight COPD patients have not been studied until now.

The primary aim of the present study was to investigate resting whole-body lipolysis in sarcopaenic COPD patients versus healthy controls, matched for age and body mass index (BMI). Secondarily, potential differences in lipolytic rate between normal and underweight COPD patients matched for disease severity were explored, since loss of FM may occur due to increased lipolysis, as previously observed in cancer patients [10]. Since oxidation of free fatty acids (FFAs) accounts for the major portion of energy requirements during low-intensity exercise, submaximal bicycle exercise was used as metabolic stressor for whole-body lipolysis.

\section{METHODS}

\section{Study population}

Seven clinically stable male COPD outpatients [11] with moderate airflow obstruction and seven healthy controls, matched for age, sex and BMI, volunteered for the present study. Additionally, six COPD patients with low BMI were recruited, matched for forced expiratory volume in one second (FEV1). Exclusion criteria for participation were glucose intolerance; diabetes mellitus; thyroid or other endocrine disorders; recent involuntary weight loss; malignancies; chronic heart failure; renal, hepatic or other gastro-intestinal disease; and recent surgery. Patients did not exhibit chronic respiratory insufficiency or receive supplemental oxygen therapy. The following pulmonary maintenance medications were used: inhaled short- and long-acting $\beta_{2}$-adrenoceptor agonists (54\%); anticholinergics by inhalation (54\%); combined inhalers of short-acting $\beta_{2}$-adrenoceptor agonists and shortacting anticholinergics ( $8 \%$ ); inhalation corticosteroids $(8 \%)$; combined inhalers of sympathicomimetics and corticosteroids (46\%); xanthines (31\%); and oral $N$-acetylcysteine $(23 \%)$. The use of pulmonary medications was equally distributed between COPD subgroups. On the evening before the test day and on the morning of the study, pulmonary maintenance medications were suspended in order to avoid potential acute effects of these on lipolysis. Written informed consent was obtained from all subjects and the study was approved by the medical ethical committee of Maastricht University Hospital (Maastricht, the Netherlands).

\section{Study design}

The study was performed in the outpatient metabolic ward of Maastricht University Hospital on two separate occasions. During the first visit, medical history was checked and physical examination undertaken by a physician. Furthermore, body composition was measured and lung function and incremental exercise tests carried out. Eligible subjects subsequently participated in the glycerol stable isotope tracer protocol, as described below.

\section{Lung function tests}

Subjects underwent spirometry for measurement of FEV1 and forced vital capacity. The highest value of at least three technically acceptable manoeuvres was used. Total lung capacity and residual volume were determined by wholebody plethysmography (MasterLab Body; Jaeger, Würzburg, Germany). Diffusing capacity of the lung for carbon monoxide was assessed by the single-breath method (MasterLab Transfer; Jaeger). All values obtained were related to a reference value and expressed as a percentage of the predicted value. In patients, arterial blood gas levels were determined using a blood gas analyser (ABL 700; Radiometer, Copenhagen, Denmark).

\section{Body composition}

Body height was determined to the nearest $0.5 \mathrm{~cm}$ with subjects standing barefoot. Body weight (BW) was measured using a beam scale (SECA, Hamburg, Germany), without shoes and in light clothing, to the nearest $0.1 \mathrm{~kg}$. BMI was calculated as the ratio of weight (in kilograms) to height (in metres) squared. FFM was measured by bioelectrical impedance analysis over a spectrum of 48 frequencies ranging 5$500 \mathrm{kHz}$ (Xitron 4000b; Xitron Technologies, San Diego, CA, USA). Resistance was measured in the supine position at the right side, as described by LUKASKI et al. [12]. In subjects with COPD, FFM was estimated from impedance measurements using the sex-specific regression equation described by STEINER et al. [13], and D.K. Dey's equation [14] was used for the healthy elderly controls. FFM index (FFMI) was calculated as the ratio of FFM to height (in metres) squared.

\section{Exercise capacity}

In order to determine the submaximal bicycle exercise load for each individual, subjects performed a standardised incremental exhaustive exercise test on an electrically braked cycle ergometer, as previously described [15].

\section{Glycerol stable isotope tracer protocol}

After an overnight fast, subjects reported to the laboratory at 07:30 $\mathrm{h}$ and were studied at rest in the supine position. A catheter was placed in an antecubital vein of the arm for stable isotope infusion. A second catheter for sampling of arterialised venous blood was placed retrogradely in a dorsal hand vein of the contralateral arm and maintained at $60^{\circ} \mathrm{C}$ in a thermoregulated box. At 08:00 h, after taking a blood sample for background enrichment of plasma glycerol, subjects were administered a single intravenous dose of $\left[{ }^{2} \mathrm{H}_{5}\right]$ glycerol $\left(1.5 \mu \mathrm{mol} \cdot \mathrm{kg} \mathrm{BW}^{-1},>99 \%\right.$ enriched; Cambridge Isotopes Inc. Andover, MA, USA) in order to prime the glycerol pool. Thereafter (time $(t)=0 \mathrm{~min}$ ), a continuous infusion of $\left[{ }^{2} \mathrm{H}_{5}\right.$ ]glycerol $\left(0.1 \mu \mathrm{mol} \cdot \mathrm{kg} \quad \mathrm{BW}^{-1} \cdot \mathrm{min}^{-1}\right)$ dissolved in $0.9 \%$ saline was started via a calibrated pump (IVAC 560; IVAC Corporation, San Diego, CA, USA). Resting blood samples were taken at $t=110$ and $120 \mathrm{~min}$. In each experiment, the exact $\left[{ }^{2} \mathrm{H}_{5}\right]$ glycerol infusion rate was determined from the glycerol concentration and enrichment in the infusate. At $t=120 \mathrm{~min}$, COPD patients started to exercise on a cycle ergometer at $50 \%$ of maximal workload $(W \max )$ for $20 \mathrm{~min}$, whereas controls exercised at an identical absolute workload $(30 \mathrm{~W})$ for the same duration. Blood samples were drawn at $t=125,130,135$ and $140 \mathrm{~min}$. The protocol continued with a $1-\mathrm{h}$ recovery period, during which blood samples were taken at $t=155,170$, 185 and $200 \mathrm{~min}$. Thereafter, controls performed a second 20min exercise test at $50 \%$ of their individual $W \max$ in order to study potential alterations in glycerol kinetics at identical relative submaximal workload. Blood samples were taken at $t=205,210,215$ and $220 \mathrm{~min}$ during exercise and at $t=235,250$, 265 and $280 \mathrm{~min}$ during a second recovery period of $1 \mathrm{~h}$. 
Plasma levels of regulatory hormones were determined at $t=110,140,200,220$ and $280 \mathrm{~min}$. During the study, subjects were allowed to drink only water.

\section{Analytical procedures}

Blood samples $(5 \mathrm{~mL})$ for the determination of $\left[{ }^{2} \mathrm{H}_{5}\right]$ glycerol enrichment and glycerol concentration were collected on heparin, immediately put on ice and centrifuged for $10 \mathrm{~min}$ at $3,120 \times g$ at $4{ }^{\circ} \mathrm{C}$. Samples for catecholamines were collected in iced ethylenediamine tetra-acetic acid tubes, centrifuged for $10 \mathrm{~min}$ at $3,120 \times g$ at $4^{\circ} \mathrm{C}$ and stored in a glutathionecontaining tube. For determination of insulin levels, $3 \mathrm{~mL}$ arterialised venous blood were put into a coagulation tube, which was centrifuged for $10 \mathrm{~min}$ at $2,340 \times g$ at room temperature. Serum was separated and centrifuged again for $5 \mathrm{~min}$ at $2,340 \times g$. All aliquots of plasma and serum were frozen immediately in liquid nitrogen, stored at $-80^{\circ} \mathrm{C}$ and transported on dry ice before assay.

Isotope enrichment of plasma glycerol was determined by gas chromatography-mass spectrometry, as described by ACKERMANS et al. [16]. Serum FFAs were measured using a colorimetric enzymatic method (NEFAC; Wako Chemicals, Neuss, Germany). Catecholamines were determined using an in-house reversed phase HPLC method with fluorescence detection. Plasma insulin concentrations were determined by radioimmunoassay (Immulite; Diagnostic Products Corporation, Los Angeles, CA, USA).

\section{Calculations}

The rate of appearance $(R a)$ of glycerol at rest was calculated by dividing the rate of infusion of $\left[{ }^{2} \mathrm{H}_{5}\right]$ glycerol by plasma glycerol enrichment. During submaximal exercise, the glycerol Ra was calculated using the single-pool non-steady-state Steele equation, adapted for stable isotope methodology as described elsewhere [17]:

$$
R_{\mathrm{a}}=\left\{V^{\prime}-V \mathrm{~d}[(C 2+C 1) / 2][(E 2-E 1) /(t 2-t 1)]\right\} /[(E 2+E 1) / 2]
$$

where $V^{\prime}$ is the infusion rate (in $\mu \mathrm{mol} \cdot \mathrm{kg} \mathrm{FFM}^{-1} \cdot \mathrm{min}^{-1}$ ), $V \mathrm{~d}$ is the volume of distribution of glycerol, $C_{1}$ and $C_{2}$ are the glycerol concentrations at $t 1$ and $t 2$, respectively, and $E 1$ and $E 2$ are the glycerol enrichments at $t 1$ and $t 2$, respectively. The effective $V \mathrm{~d}$ was assumed to be $230 \mathrm{~mL} \cdot \mathrm{kg} \mathrm{BW}^{-1}$ [18].

\section{Statistics}

Results are presented as mean \pm SEM. One-way ANOVA was used to determine differences in baseline characteristics and substrate and hormone concentrations between normal-weight patients, underweight patients and controls. The leastsignificant-difference multiple comparison test was used as a post hoc test. Mixed-design ANOVA for repeated measures was performed in order to analyse potential differences in glycerol $R a$ between the three study groups. Groups were entered as between-group variables, whereas individual glycerol $R a$ at various time-points of the protocol were used as within-group variables. This analysis was performed for each of the phases of the protocol (rest, submaximal exercise and recovery) and specifically focussed on significant between-group differences in glycerol Ra during any of these phases. Levene's test showed homogeneity of variance of repeated measures of glycerol $R$ a. In order to assess the variation explained by between-group differences and the variation explained by unsystematic factors, F-ratios were calculated. Mauchley's test of sphericity was performed to assess equality of variances of the differences between groups. Since the condition of sphericity was not met, Greenhouse-Geisser correction was applied in the production of F-ratios.

\section{RESULTS}

The general characteristics of all subjects are shown in table 1 . As expected, the normal-weight COPD patients could be typified as sarcopaenic based on a comparable FM index (FMI) but reduced FFMI in comparison to controls. In the underweight COPD patients, FM/FMI and FFM/FFMI were significantly decreased in comparison to the other COPD group and controls (fig. 1). Lung function and arterial blood gas levels were equally impaired in both COPD groups. Functional capacity was impaired in COPD and was more reduced in underweight patients than in sarcopaenic patients. This was probably the result of the difference in FFM, since maximal oxygen consumption was related to FFMI $(\mathrm{r}=0.679 ; \mathrm{p}<0.05)$.

The resting post-absorptive $R$ a of glycerol was comparable in sarcopaenic COPD patients $\left(4.1 \pm 0.6 \mu \mathrm{mol} \cdot \mathrm{kg} \mathrm{FFM}{ }^{-1} \cdot \mathrm{min}^{-1}\right)$

\begin{tabular}{|c|c|c|c|}
\hline & \multirow[t]{2}{*}{ Controls } & \multicolumn{2}{|c|}{ COPD patients } \\
\hline & & Sarcopaenic & Underweight \\
\hline Subjects $n$ & 7 & 7 & 6 \\
\hline Age yrs & $64 \pm 2$ & $64 \pm 4$ & $70 \pm 4$ \\
\hline \multicolumn{4}{|l|}{ Body composition } \\
\hline Height $\mathrm{cm}$ & $173.7 \pm 2.2$ & $172.9 \pm 1.9$ & $168.1 \pm 1.5^{\#}$ \\
\hline Weight kg & $85.5 \pm 5.6$ & $82.5 \pm 3.5$ & $58.2 \pm 2.1^{\# \# \#, \star *}$ \\
\hline $\mathrm{BMI} \mathrm{kg} \cdot \mathrm{m}^{-2}$ & $28.2 \pm 1.2$ & $27.5 \pm 0.9$ & $20.6 \pm 0.7^{\# \# \#, \star \star \star \star}$ \\
\hline FFM kg & $62.6 \pm 2.7$ & $56.1 \pm 2.4^{\circ}$ & $45.3 \pm 1.5^{\# \# \#, \star *}$ \\
\hline $\mathrm{FFMI} \mathrm{kg} \cdot \mathrm{m}^{-2}$ & $20.7 \pm 0.5$ & $18.8 \pm 0.8^{\#}$ & $16.0 \pm 0.4^{\# \# \#, *}$ \\
\hline $\mathrm{FM} \mathrm{kg}$ & $22.9 \pm 3.3$ & $26.4 \pm 2.9$ & $12.9 \pm 0.8^{\#, \star \star}$ \\
\hline $\mathrm{FMl} \mathrm{kg} \cdot \mathrm{m}^{-2}$ & $7.5 \pm 0.9$ & $8.8 \pm 0.9$ & $4.6 \pm 0.3^{\#, \star \star}$ \\
\hline \multicolumn{4}{|l|}{ Pulmonary function } \\
\hline FEV $1 \%$ pred & $105 \pm 4$ & $53 \pm 5^{\# \# \#}$ & $51 \pm 5^{\# \# \#}$ \\
\hline $\mathrm{FEV}_{1} / \mathrm{FVC}_{0} \%$ & $73.0 \pm 1.8$ & $43.0 \pm 1.9^{\# \# \#}$ & $34.4 \pm 4.6 \ldots \#$ \\
\hline$D \mathrm{~L}, \mathrm{CO} \%$ pred & $117 \pm 5$ & $62 \pm 7^{\# \# \#}$ & $62 \pm 4^{\# \# \#}$ \\
\hline RV/TLC \% & $36.3 \pm 1.6$ & $43.2 \pm 3.5$ & $51.0 \pm 10.0$ \\
\hline $\mathrm{Pa}_{1} \mathrm{O}_{2} \mathrm{kPa}$ & & $8.5 \pm 7.4$ & $8.5 \pm 7.8$ \\
\hline $\mathrm{Pa}_{1} \mathrm{CO}_{2} \mathrm{kPa}$ & & $5.1 \pm 0.2$ & $5.1 \pm 0.1$ \\
\hline \multicolumn{4}{|l|}{ Exercise capacity } \\
\hline Peak workload \% pred & $129 \pm 9$ & $48 \pm 5^{\# \# \#}$ & $44 \pm 4^{\# \# \#}$ \\
\hline$V^{\prime} \mathrm{O}_{2}$ max \% pred & $110 \pm 6$ & $62 \pm 5^{\# \# \#}$ & $57 \pm 3^{\# \# \#}$ \\
\hline
\end{tabular}

Data are presented as mean \pm SEM. COPD: chronic obstructive pulmonary disease; BMI: body mass index; FFM: fat-free mass (assessed by bioelectrical impedance analysis); FFMI: FFM index; FM: fat mass; FMI: FM index; FEV1: forced expiratory volume in one second; \% pred: \% predicted; FVC: forced vital capacity; $\mathrm{DL}, \mathrm{CO}$ : diffusing capacity of the lung for carbon monoxide; RV: residual volume; TLC: total lung capacity; $\mathrm{Pa}, \mathrm{O}_{2}$ : arterial oxygen tension; $\mathrm{Pa}_{\mathrm{a}} \mathrm{CO}_{2}$ : arterial carbon dioxide tension; $\mathrm{V}^{\prime} \mathrm{O}_{2}$,max: maximal oxygen consumption $*: p<0.05 ; * *: p<0.01 ; * * *: p<0.001$ versus sarcopaenic patients \#: $p<0.05 ;{ }^{\# \# \#: p<0.001 ;}{ }^{\circ}: p=0.06$ versus controls. 


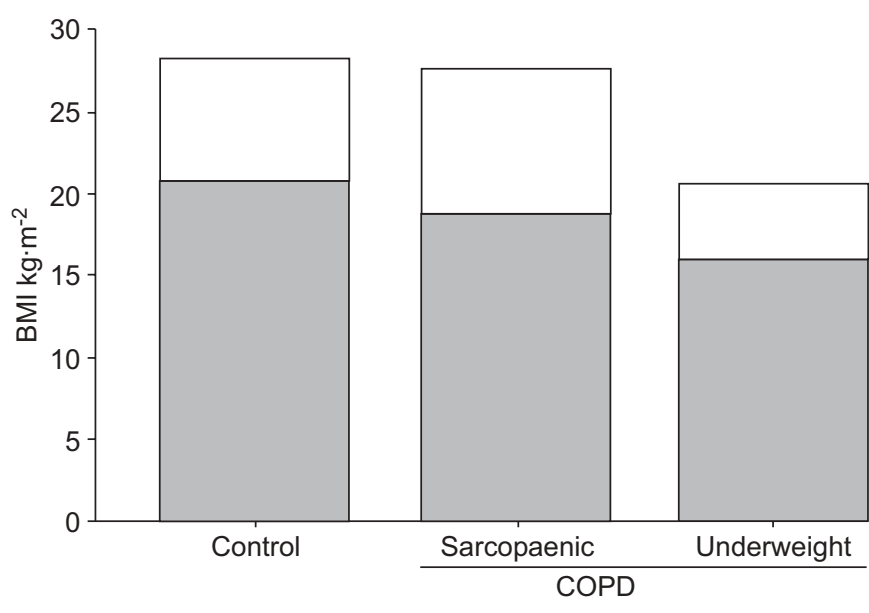

FIGURE 1. Body composition of the study groups. The contributions of fat mass index (FMl; $\square$ ) and fat-free mass index (FFMl; $\square$ ) to body mass index (BMI) are shown. The BMl of sarcopaenic chronic obstructive pulmonary disease (COPD) patients was comparable to that of controls, although FFMI was significantly reduced. Underweight COPD patients were characterised by reduced BMI, FFMI and FMI. See table 1 for SEM and p-values.

and controls $\left(3.3 \pm 0.2 \mu \mathrm{mol} \cdot \mathrm{kg} \mathrm{FFM}{ }^{-1} \cdot \mathrm{min}^{-1} ; \mathrm{p}=0.25\right.$; fig. 2). Glycerol $R \mathrm{a}$ in underweight COPD patients $(4.3 \pm 0.5 \mu \mathrm{mol} \cdot \mathrm{kg}$ $\mathrm{FFM}^{-1} \cdot \mathrm{min}^{-1}$; NS) was comparable to that of the other groups. Mixed-design ANOVA for repeated measures revealed a nonsignificant effect of study group on whole-body glycerol $R a$ at rest $(F(1,2)=308.47$; NS). Fasting plasma levels of FFAs and glycerol were comparable in the three groups (table 2). In underweight COPD patients, catecholamine concentrations were significantly increased compared to sarcopaenic patients and controls. In addition, insulin levels were significantly increased in sarcopaenic patients, whereas insulin concentrations in underweight COPD patients were decreased.

Submaximal bicycle exercise resulted in significant increases in glycerol $R a$ in all three groups (fig. 2). The proportional increase in glycerol $R$ a during submaximal exercise was slightly less in sarcopaenic COPD patients $(59 \pm 18 \%)$ in comparison with underweight patients $(82 \pm 22 \%$; NS). In controls, the relative increment in glycerol $R$ a was even greater during submaximal exercise at both identical absolute workload (107 $\pm 22 \%$; NS) and identical proportional load $(177 \pm 39 \%$; $<<0.05$ for both COPD groups). As a consequence, end-exercise glycerol $R$ a were lower in sarcopaenic patients $\left(6.8 \pm 1.2 \mu \mathrm{mol} \cdot \mathrm{kg} \mathrm{FFM}{ }^{-1} \cdot \mathrm{min}^{-1}\right)$ than in underweight patients $\left(7.6 \pm 1.0 \mu \mathrm{mol} \cdot \mathrm{kg} \mathrm{FFM}{ }^{-1} \cdot \mathrm{min}^{-1}\right)$ and controls (30 W: $7.7 \pm 1.3 \mu \mathrm{mol} \cdot \mathrm{kg} \mathrm{FFM}^{-1} \cdot \mathrm{min}^{-1} ; 50 \%$ Wmax: $7.9 \pm$ $1.1 \mu \mathrm{mol} \cdot \mathrm{kg} \mathrm{FFM}{ }^{-1} \cdot \mathrm{min}^{-1}$ ), but differences were nonsignificant (fig. 2). Following exercise, glycerol $R$ a recovered to baseline in all groups and were comparable (fig. 2). No significant effects of study group on whole-body glycerol $R$ a were observed during submaximal exercise at identical absolute workload $(F(1$, $2)=201.96$; NS) and identical relative workload $(F(1,2)=213.76$; NS) and during recovery periods $(F(1,2)=189.71$, NS; $F(1,2)=$ 212.86 , NS, respectively). Plasma concentrations of FFAs, glycerol and catecholamines increased significantly following submaximal exercise in all groups, and end-exercise levels were also identical (table 2).
On bivariate correlation analysis in the total study population, resting glycerol $R$ a was related to plasma adrenalin concentration $(\mathrm{r}=0.520 ; \mathrm{p}<0.05)$ and basal glycerol level $(\mathrm{r}=0.760$ $\mathrm{p}<0.001)$, whereas correlations with BMI, FFM/FFMI and FM/FMI were absent. End-exercise glycerol $R a$ was significantly related to post-exercise glycerol $(\mathrm{r}=0.762 ; \mathrm{p}<0.01)$ and FFA plasma levels $(r=0.631 ; p<0.05)$ and to resting noradrenalin concentration $(\mathrm{r}=0.618 ; \mathrm{p}<0.05)$ in COPD patients.

\section{DISCUSSION}

The present study is the first to investigate lipid kinetics using glycerol stable isotope tracer methodology in patients with COPD. In addition, the contribution of derangements in wholebody lipolysis to body composition has not previously been studied in COPD. No differences in resting and exerciseinduced lipolysis were observed between sarcopaenic COPD patients and age-matched controls. Thus, in clinically stable normal-weight COPD patients, (relative) maintenance of FM with evidence of muscle wasting is not related to altered adipocyte lipolysis.

Total body FM is determined by the balance between lipid synthesis and degradation. Lipids are stored in the adipocytes as triglycerides and constitute the main fuel reserve of the body. Following hormonal stimulation, the stored triglycerides are hydrolysed to their components, fatty acids and glycerol, and this process is called lipolysis. The released fatty acids are either used for mitochondrial $\beta$-oxidation to produce ATP or re-esterified to triacylglycerol and restored. FFAs are the major source of energy for resting muscle. It has been consistently shown that muscle fat oxidative capacity is reduced in COPD patients [8], partly as an adaptation to a more sedentary lifestyle due to disease-related symptoms. Although the effects of physical inactivity on adipose tissue lipolysis in COPD have not been studied, the available evidence suggests that wholebody lipolytic rate is not related to training status [19]. No difference in exercise-induced lipolysis was observed between untrained and endurance-trained healthy subjects, although fat oxidation was enhanced in the latter group [20].

Previously, SCHIFFELERS et al. [9] reported a reduced increase in plasma fatty acid levels and a blunted thermogenic response during $\beta$-adrenergic stimulation in normal-weight COPD patients with a high FM compared to controls. The authors suggested that disturbed lipolytic responsiveness contributed to the development or maintenance of increased FM in the sarcopaenic COPD patient subgroup. In contrast to the present study, no patients with a reduced FM were studied and wholebody lipolysis was not assessed. However, the results of the present study are in line with these previous observations. Although whole-body lipolytic rate was comparable between groups, homeostatic control of lipolysis was altered in sarcopaenic COPD patients, as indicated by hyperinsulinaemia. Thus the inhibitory effect of insulin on lipolytic rate seemed impaired in sarcopaenic COPD patients. In addition, the lipolytic response to exercise tended to be decreased in this subgroup.

In contrast to the present results, JAKOBSSON et al. [21] reported increased turnover rate and plasma levels of FFAs in normalweight COPD patients (BMI $23.6 \mathrm{~kg} \cdot \mathrm{m}^{-2}$ ), suggestive of an increased rate of lipolysis. The fact that the patients included 


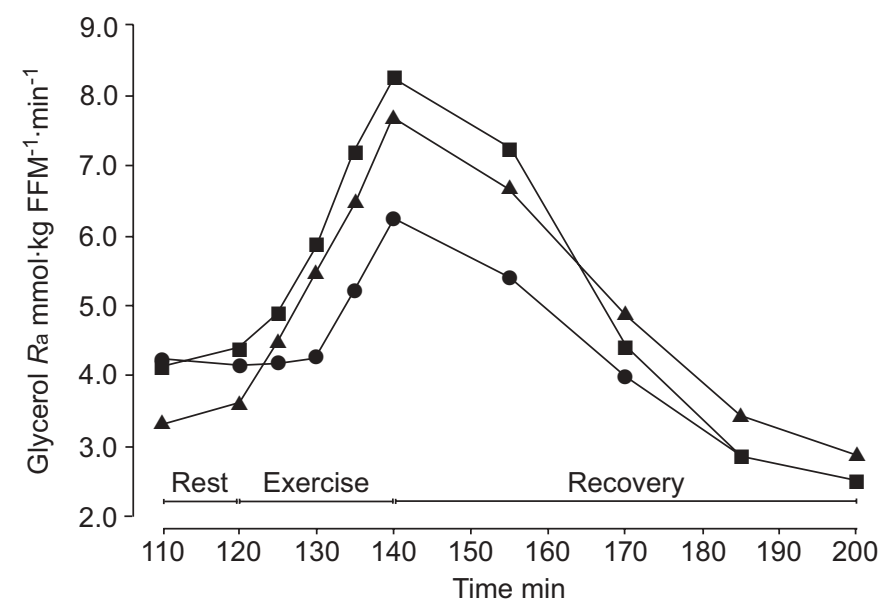

FIGURE 2. Whole-body lipolysis measured by rate of appearance (Ra) of glycerol at rest, during submaximal cycle exercise and during recovery from exercise in healthy controls $(\mathbf{\Lambda} ; n=7)$ and sarcopaenic $(\bullet ; n=7)$ and underweight chronic obstructive pulmonary disease patients $(\mathbf{\square} ; n=6)$. For clarity, SEM are not shown. No significant differences were observed between groups at any point in the study.

were chronically hypoxaemic may account for the distinct results compared to those found in the normoxaemic patients in the present study. In healthy subjects, elevated levels of FFA were observed during chronic hypobaric hypoxia, probably related to enhanced adrenalin-induced lipolysis [22].

Lipolytic rate was not enhanced in underweight COPD patients in comparison with normal-weight patients or controls, despite significantly elevated catecholamine levels. Since catecholamines are the primary stimulators of lipolysis via $\beta$-adrenoceptors, alterations in sympathetic tone may result in changes in FM and BW in COPD patients. Indeed, HOFFORD et al. [23] reported almost doubled plasma noradrenalin levels in underweight patients with severe COPD in comparison with healthy normal-weight control subjects. However, the results of the present study suggest reduced sensitivity to circulating catecholamines and confirm the observations of SCHIFFELERS et al. [9]. Owing to chronic overstimulation of the sympathetic nervous system in COPD [24] and the long-term usage of $\beta_{2^{-}}$ agonists for bronchodilatation, $\beta$-adrenoceptors may become desensitised and, subsequently, the lipolytic response following hormonal stimulation might be reduced [25].

Since the contribution of impaired lipolysis to the sarcopaenic phenotype of COPD patients is unlikely, selective wasting of FFM rather than preservation of FM seems to be the predominant pathophysiological mechanism. Indeed, increased whole-body myofibrillar protein breakdown, assessed using a methylhistidine stable isotope tracer protocol, has been reported in underweight COPD patients with reduced FFM and FM, in comparison with normal-weight patients and controls with preserved FFM [5]. In addition, increased cellular [6] and muscular protein catabolism [7] was observed in COPD patients with evidence of muscle atrophy. This suggests that increased muscle protein breakdown is the trigger in the body compositional shift in COPD, towards reduced FFM.

\begin{tabular}{|c|c|c|c|}
\hline \multirow[t]{3}{*}{ TABLE 2} & \multicolumn{3}{|c|}{$\begin{array}{l}\text { Resting and end-exercise plasma free fatty acid } \\
\text { (FFA), glycerol and hormone concentrations }\end{array}$} \\
\hline & \multirow[t]{2}{*}{ Controls } & \multicolumn{2}{|c|}{ COPD patients } \\
\hline & & Sarcopaenic & Underweight \\
\hline Subjects n & 7 & 7 & 6 \\
\hline \multicolumn{4}{|l|}{ Resting state } \\
\hline FFA mM & $1.04 \pm 0.14$ & $1.08 \pm 0.13$ & $0.99 \pm 0.11$ \\
\hline Glycerol mM & $79.9 \pm 6.4$ & $85.0 \pm 9.5$ & $97.1 \pm 11.1$ \\
\hline Insulin pM & $47 \pm 9$ & $76 \pm 12^{\circ}$ & $22 \pm 6^{\star \star}$ \\
\hline Adrenalin nM & $0.45 \pm 0.07$ & $0.52 \pm 0.12$ & $1.01 \pm 0.24^{\sigma / *}$ \\
\hline Noradrenalin nM & $0.35 \pm 0.09$ & $0.85 \pm 0.21$ & $1.22 \pm 0.46^{\circ}$ \\
\hline \multicolumn{4}{|l|}{ End-exercise $^{\#}$} \\
\hline FFA mM & $1.79 \pm 0.28$ & $1.45 \pm 0.15$ & $1.42 \pm 0.25$ \\
\hline Glycerol mM & $230.6 \pm 41.2$ & $207.7 \pm 40.5$ & $229.1 \pm 49.7$ \\
\hline Insulin pM & $51 \pm 8$ & $66 \pm 13$ & $19 \pm 3^{9 * \star \star}$ \\
\hline Adrenalin nM & $0.85 \pm 0.18$ & $3.68 \pm 2.40$ & $2.88 \pm 1.00$ \\
\hline Noradrenalin $\mathrm{nM}$ & $1.34 \pm 0.21$ & $2.41 \pm 0.51$ & $2.18 \pm 0.86$ \\
\hline
\end{tabular}

Data are presented as mean \pm SEM. COPD: chronic obstructive pulmonary disease. ${ }^{\#}$ : values after exercise at identical absolute workload are shown for controls. $?: p<0.05$ versus controls. *: $p<0.05 ;{ }^{* *}: p<0.01$ versus sarcopaenic patients

The present study assessed potential differences in lipolytic rate in clinically stable sarcopaenic COPD patients without recent weight loss. However, the present body composition of these COPD patients may result from foregoing episodes of shifts in body fat and fat-free tissues. During acute exacerbations of the disease, a combination of enhanced hypoxaemia, increased sympathetic tone, more frequent use of $\beta_{2}$-agonists as reliever therapy, administration of systemic corticosteroids and a reduced dietary intake may induce short-term bursts of increased lipolysis, resulting in degradation of body FM and weight loss. Thus it might be interesting to study potential periods of deranged lipid metabolism during acute exacerbations in relation to longitudinal changes in body composition in COPD in the future.

In summary, resting and exercise-induced whole-body lipolytic rate were comparable in sarcopaenic chronic obstructive pulmonary disease patients, underweight patients and matched controls, despite significant alterations in endocrinological control of lipolysis. Disturbances in lipolytic rate do not contribute to alterations in body composition in chronic obstructive pulmonary disease.

\section{REFERENCES}

1 Schols AM, Broekhuizen R, Weling-Scheepers CA, Wouters EF. Body composition and mortality in chronic obstructive pulmonary disease. Am J Clin Nutr 2005; 82: 53-59.

2 Vermeeren MA, Creutzberg EC, Schols AM, et al. Prevalence of nutritional depletion in a large out-patient population of patients with COPD. Respir Med 2006; 100: 1349-1355. 
3 Schols AM, Soeters PB, Dingemans AM, Mostert R, Frantzen PJ, Wouters EF. Prevalence and characteristics of nutritional depletion in patients with stable COPD eligible for pulmonary rehabilitation. Am Rev Respir Dis 1993; 147: 1151-1156.

4 Vestbo J, Prescott E, Almdal T, et al. Body mass, fat-free body mass, and prognosis in patients with chronic obstructive pulmonary disease from a random population sample: findings from the Copenhagen City Heart Study. Am J Respir Crit Care Med 2006; 173: 79-83.

5 Rutten EP, Franssen FM, Engelen MP, Wouters EF, Deutz NE, Schols AM. Greater whole-body myofibrillar protein breakdown in cachectic patients with chronic obstructive pulmonary disease. Am J Clin Nutr 2006; 83: 829-834.

6 Bolton CE, Broekhuizen R, Ionescu AA, et al. Cellular protein breakdown and systemic inflammation are unaffected by pulmonary rehabilitation in COPD. Thorax 2007; 62: 109-114.

7 Doucet M, Russell AP, Léger B, et al. Muscle atrophy and hypertrophy signaling in patients with chronic obstructive pulmonary disease. Am J Respir Crit Care Med 2007; 176: 261-269.

8 Maltais F, LeBlanc P, Whittom F, et al. Oxidative enzyme activities of the vastus lateralis muscle and the functional status in patients with COPD. Thorax 2000; 55: 848-853.

9 Schiffelers SL, Blaak EE, Baarends EM, et al. $\beta$ Adrenoceptor-mediated thermogenesis and lipolysis in patients with chronic obstructive pulmonary disease. Am J Physiol Endocrinol Metab 2001; 280: E357-E364.

10 Legaspi A, Jeevanandam M, Starnes HF Jr, Brennan MF. Whole body lipid and energy metabolism in the cancer patient. Metabolism 1987; 36: 958-963.

11 American Thoracic Society. Standards for the diagnosis and care of patients with chronic obstructive pulmonary disease. Am J Respir Crit Care Med 1995; 152: S77-S121.

12 Lukaski HC, Johnson PE, Bolonchuk WW, Lykken GI. Assessment of fat-free mass using bioelectrical impedance measurements of the human body. Am J Clin Nutr 1985; 41: 810-817.

13 Steiner MC, Barton RL, Singh SJ, Morgan MD. Bedside methods versus dual energy X-ray absorptiometry for body composition measurement in COPD. Eur Respir J 2002; 19: 626-631.
14 Kyle UG, Bosaeus I, De Lorenzo AD, et al. Bioelectrical impedance analysis - part I: review of principles and methods. Clin Nutr 2004; 23: 1226-1243.

15 Franssen FM, Broekhuizen R, Janssen PP, Wouters EF, Schols AM. Effects of whole-body exercise training on body composition and functional capacity in normalweight patients with COPD. Chest 2004; 125: 2021-2028.

16 Ackermans MT, Ruiter AF, Endert E. Determination of glycerol concentrations and glycerol isotopic enrichments in human plasma by gas chromatography/mass spectrometry. Anal Biochem 1998; 258: 80-86.

17 Wolfe RR. Radioactive and Stable Isotope Tracers in Biomedicine: Principles and Practice of Kinetic Analysis. New York, Wiley-Liss, 1992.

18 Romijn JA, Coyle EF, Sidossis LS, et al. Regulation of endogenous fat and carbohydrate metabolism in relation to exercise intensity and duration. Am J Physiol 1993; 265: E380-E391.

19 Horowitz JF, Klein S. Lipid metabolism during endurance exercise. Am J Clin Nutr 2000; 72: Suppl. 2, 558S-563S.

20 Klein S, Coyle EF, Wolfe RR. Fat metabolism during lowintensity exercise in endurance-trained and untrained men. Am J Physiol 1994; 267: E934-E940.

21 Jakobsson P, Jorfeldt L, von Schenck H. Fat metabolism and its response to infusion of insulin and glucose in patients with advanced chronic obstructive pulmonary disease. Clin Physiol 1995; 15: 319-329.

22 Roberts AC, Butterfield GE, Cymerman A, Reeves JT, Wolfel EE, Brooks GA. Acclimatization to 4,300-m altitude decreases reliance on fat as a substrate. J Appl Physiol 1996; 81: 1762-1771.

23 Hofford JM, Milakofsky L, Vogel WH, Sacher RS, Savage GJ, Pell S. The nutritional status in advanced emphysema associated with chronic bronchitis. A study of amino acid and catecholamine levels. Am Rev Respir Dis 1990; 141: 902-908.

24 Andreas S, Anker SD, Scanlon PD, Somers VK Neurohumoral activation as a link to systemic manifestations of chronic lung disease. Chest 2005; 128: 3618-3624.

25 Holgate ST, Stubbs WA, Wood PJ, McCaughey ES, Alberti KG, Tattersfield AE. Airway and metabolic resistance to intravenous salbutamol: a study in normal man. Clin Sci (Lond) 1980; 59: 155-161. 